\title{
Where does all the biofuel go? Fuel efficiency gains and its effects on global agricultural production
}

\author{
Jerome Dumortier and Miguel Carriquiry and Amani Elobeid
}

October 7, 2021

\begin{abstract}
Increasing biofuel production over the last decade and biofuel policies in Brazil, the European Union, and the United States have changed the global agricultural landscape in terms of landuse, commodity prices, and trade. Increasing fuel efficiency and electrification of the vehicle stock is projected to lower gasoline, diesel, and biofuel demand in the future. In this analysis, we quantify the effects of a $30 \%$ reduction in ethanol consumption in the U.S. and the European Union triggered by higher vehicle fleet fuel efficiency on global agricultural markets. Our results show decreases in global commodity prices by $1.9 \%-6.6 \%$ and a slight decrease in global cropland by $0.3 \%$. Major changes occur in trade patterns with U.S. corn exports increasing by $30.3 \%$. Global greenhouse gas emissions are lower due to the overall reduction in cropland. Gasoline and diesel consumption of the vehicle fleet is not changing rapidly but is a long-term process because vehicles are on average in operation for 10 or more years. Consequently, there are important long-term policy implications from changes in fuel efficiency requirements or ethanol blending limits that affect commodity prices, trade, and greenhouse gas emissions.
\end{abstract}

\section{Introduction}

Over the last decade, expanding biofuel production has significantly changed the agricultural landscape in the United States (U.S.) and elsewhere. Between 2000 and 2018, the percentage of U.S. corn used for ethanol rose from $6.5 \%$ to $37.6 \%$ (USDA, 2020b). The increased biofuel production has attracted attention from researchers and policy makers due to the economic and environmental consequences in terms of higher crop prices (Condon et al., 2015), altered trade patterns (Elobeid and Tokgoz, 2008; Keeney and Hertel, 2009), changes in land allocation (Fabiosa et al., 2010), and carbon emissions from land-use change (Searchinger et al., 2008; Hertel et al., 2010; Dumortier et al., 2011; Carriquiry et al., 2019). Future changes in the transportation sector, especially increasing fuel efficiency and vehicle electrification, are projected to reduce U.S. gasoline and biofuel use (EIA, 2018). Similar trends are observed in the European Union (EU) and to a lesser extent in Brazil (European Commission, 2016; EPE, 2016). Current research does not account for those changes in the transportation sector and its effects on biofuel use and agricultural markets. Our

This is the author's manuscript of the article published in final edited form as:

Dumortier, J., Carriquiry, M., \& Elobeid, A. (2021). Where does all the biofuel go? Fuel efficiency gains and its effects on global agricultural production. Energy Policy, 148, 111909. https://doi.org/10.1016/j.enpol.2020.111909 
analysis addresses this gap given the aforementioned importance of biofuels for agriculture by using a global agricultural trade model.

Currently, there is a $10 \%$ ethanol blending limit on all U.S. motor gasoline - the so-called "blend wall" - that was reached in 2016 (USDA, 2020b; EIA, 2020). The consequence of hitting the blend wall is that future U.S. ethanol demand is now directly linked to the consumption of gasoline in the absence of any policy changes. This potentially poses an economic challenge for farmers because vehicle fuel efficiency is increasing more rapidly than vehicle miles traveled. Thus, gasoline consumption in the transportation sector is expected to decrease by $31.1 \%$ between 2016 and 2050 in the reference case of the U.S. Energy Information Administration (EIA) 2018 Annual Energy Outlook (AEO) (EIA, 2018) (Panel (a), Figure 1). The decrease in gasoline consumption is even more pronounced under EIA's low economic growth and high oil price scenarios. The declining demand for gasoline due to higher fuel efficiency is exacerbated by increasing sales of alternative fuel light-duty vehicles such as electric vehicles. Although small in absolute numbers, sales of such vehicles are expected to grow annually at 11.1\% between 2016 and 2050 (EIA, 2018). The projected increase in flex-fuel vehicles - cars able to use up to $85 \%$ ethanol (E85)- will not compensate for the decline in biofuel use (Panel (b), Figure 1).

Long-term changes in biofuel demand are also occurring in the EU and Brazil although for different reasons. The situation in the EU is similar to the U.S. in the sense that demand is limited because of increasing fuel efficiency. The International Energy Agency notes that "conventional biofuels may fall in the EU after 2020 because of a less favourable policy landscape and the increasing efficiency of vehicles" (IEA Bioenergy, 2019). In contrast to the U.S. and the EU, ethanol consumption in Brazil, which is the second largest ethanol producer after the U.S., is projected to increase mainly due to the implementation of policies encouraging biofuel production. The introduction of flex-fuel vehicles in Brazil has been very successful and accounted for $93.5 \%$ of vehicle sales in 2014, which results in a projected increase of Brazilian ethanol consumption (Panels (c) and (d), Figure 1) (ANFAVEA, 2015; EPE, 2016). In 2016, the Brazilian Energy Research Office (EPE) projected the consumption of hydrous ethanol (used in ethanol-only vehicles) to continue to grow in Brazil whereas the consumption of anhydrous ethanol (blended with gasoline) was expected to peak in 2040 (Panel (c), Figure 1) (EPE, 2016).

Given the economic and environmental implications of biofuels on agriculture, the objective of this paper is to quantify the possible effects of the likely $30 \%$ decline in U.S. and EU ethanol demand on crop prices, land-use, trade, and greenhouse gas (GHG) emissions in the U.S. and globally due to increasing fuel efficiency and a changing vehicle stock composition. The magnitude of the effects warrants attention by farmers as well as state and federal policy makers. A decline in the demand for corn ethanol as is suggested in the EIA reference case under increasing commodity yields can have potentially large impacts on commodity prices and farmer welfare. Along the same lines, a reduction in the usage of corn for ethanol production can lead to a lower corn price and thus, result in lower prices for consumers for meat and dairy items because corn is used as a feed input for livestock. The paper also addresses the effect of allowing year-round sale of E15 by the U.S. Environmental Protection Agency in May 2019 (EPA, 2019). There have been various policy discussions surrounding road transportation including subsidizing electric vehicles or changing fuel efficiency standards. These policies would have long-term implications with regard to gasoline 
(a) USA: Gasoline Use

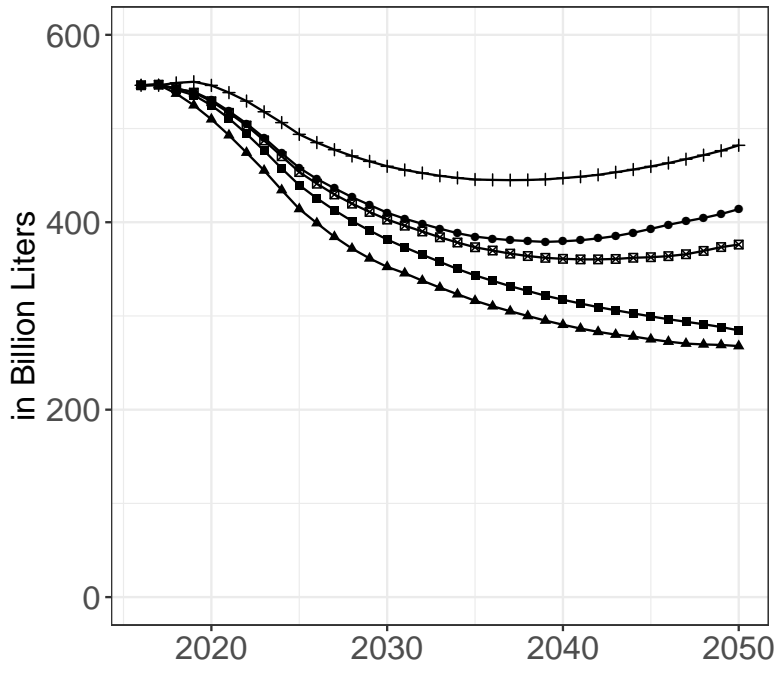

(b) USA: Source of Ethanol (from Corn)

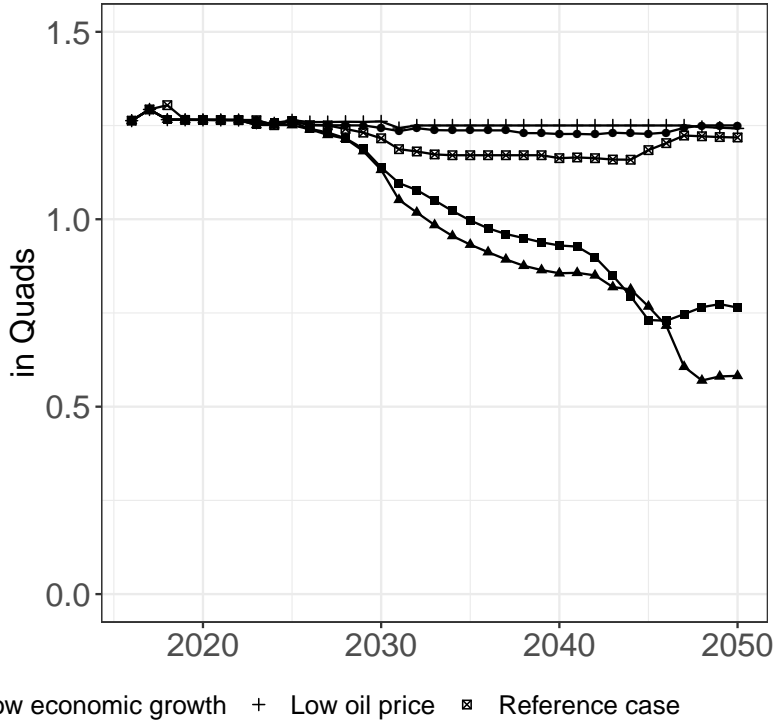

(d) Brazil: Sales by Vehicle Type

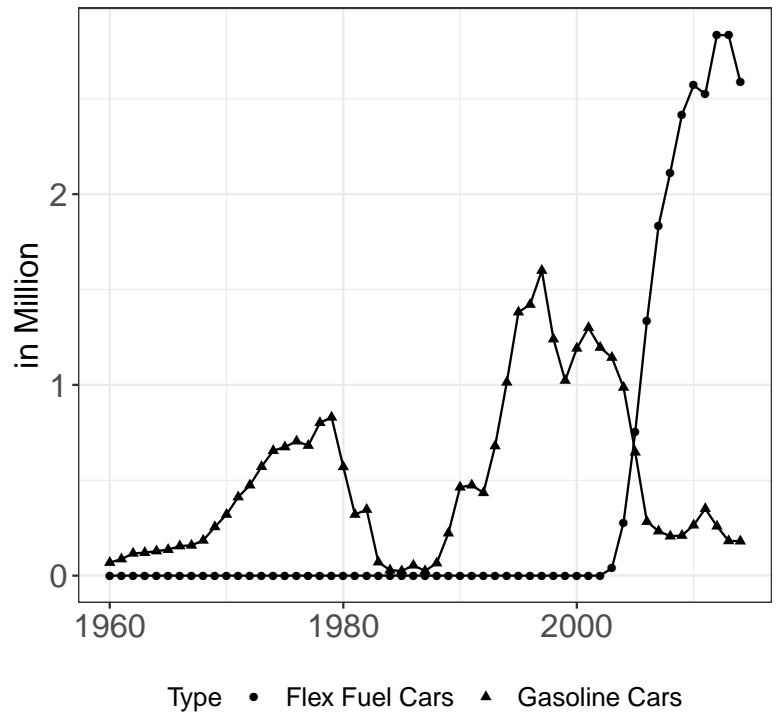

Figure 1. Panel (a): Projected U.S. gasoline consumption in the transportation sector (including light duty vehicles, commercial light trucks, freight trucks, aviation, transit bus, intercity bus, school bus, and recreation boats) between 2016 and 2050 under various macroeconomic scenarios (EIA, 2018). Panel (b): Projected energy from U.S. corn ethanol (EIA, 2018). Panel (c): Projected use of gasoline (type A and C) as well as ethanol (anhydrous and hydrous) in Brazil (EPE, 2016). Panel (d): Reported sales of flex fuel and gasoline vehicles in Brazil (ANFAVEA, 2015). 
and ethanol use. Policy decisions taken today will have small immediate effects but larger impacts in future decades as new fuel efficiency standards or vehicle technologies (e.g., battery electric vehicles) spread through the vehicle stock slowly due to the long lifespan of cars.

To quantify our objective, we incorporate EIA's transportation model estimates about future biofuel use in the U.S. and the EU into an established agricultural outlook modeling system, i.e., the CARD Model, which was developed at the Center for Agricultural and Rural Development (CARD) at Iowa State University. As discussed earlier, current projections suggest that Brazil will not see a decline in ethanol consumption by 2050. The combination of the CARD Model and the output from the EIA models allows us to compare a baseline of current ethanol use with a scenario that results in a decrease in ethanol consumption especially in the U.S. and the EU. A greenhouse gas (GHG) model is then used to calculate the resulting change in GHG emissions from a decline in the ethanol demand. To the best of our knowledge, this paper is the first to quantify the impacts on global agricultural markets and GHG emissions of reduced ethanol consumption in the U.S. and the EU due to higher fuel efficiency.

\section{Background and Literature Review}

Before outlining the modeling approach and the results, this section provides background information on the historical development and future projections of biofuels in the U.S., the EU, and Brazil. Although expanding in size, the combined biofuel market of China and India is expected to remain small compared to the three countries covered in this analysis (IEA, 2018). Scenarios developed for the 2018 World Energy Outlook (WEO) by the International Energy Agency expect the combined share of global biofuel consumption in China and India to be $9 \%$ under current policies and 13\% under a "New Policies" scenario (planned policies influencing future energy systems) and include the "Nationally Determined Contributions under the Paris Agreement" (IEA, 2018). ${ }^{1}$

\subsection{Ethanol in the United States}

Annual corn ethanol production in the U.S. increased on average by $28.5 \%$ between 2006 and 2010 and by $2.2 \%$ between 2010 and 2015 (EIA, 2019). The increase in production in the U.S. was triggered by high gasoline prices, a ban on methyl tertiary-butyl ether (MTBE) and various government policies providing support for the domestic ethanol industry (Elobeid and Tokgoz, 2008; Serra et al., 2011; Roberts and Schlenker, 2013; Beckman, 2015). These policies included blending mandates established under the Renewable Fuel Standard as well as import restrictions in the form of $2.5 \%$ ad-valorem tariff, a $\$ 0.54$ per gallon tariff (Elobeid and Tokgoz, 2008), and a blenders credit, which hovered around $\$ 0.45-0.51$ per gallon, and which ended in 2011 (Bielen et al., 2018). After the rapid expansion between 2006 and 2010, the subsequent slowdown in ethanol production can be attributed to ethanol use in gasoline approaching the blend-wall and a decrease in the profitability of ethanol production because of a decline in gasoline prices since

\footnotetext{
${ }^{1}$ Nationally Determined Contributions are individual country pledges of steps contributing to the goals of the 2015 Paris Agreement, which include keeping the increase in global temperature below $2^{\circ} \mathrm{C}$, ultimately limiting the increase to $1.5^{\circ} \mathrm{C}$, and achieving net zero emissions in the second half of the century.
} 
2012 among other factors (Beckman, 2015). As hypothesized in this analysis, the peak of ethanol consumption has been reached in the U.S. and the slowdown in expansion due to the blend wall in combination with increasing fuel efficiency are the first signs of the future decline in ethanol consumption.

The additional demand for corn from the U.S. ethanol industry has led to a multitude of economic and environmental effects. One of the more important economic effects has been the increase in global commodity prices (Condon et al., 2015). A review of studies estimating the relationship between commodity (food) prices and higher ethanol production is presented in Zilberman et al. (2013) and Condon et al. (2015). Zilberman et al. (2013) argue that the introduction of corn ethanol has had a significant impact on food commodity prices but that the effects of economic growth and oil prices are even more important reasons for the increase. Condon et al. (2015) conclude that an expansion of corn ethanol by one billion gallons (3.79 billion liters) in the U.S. increases food prices between $3 \%$ and $4 \%$. Their estimates are based on a meta-analysis reviewing 29 published studies. Higher commodity prices also led to an increase in land values especially in the U.S. Midwest (Du et al., 2008; Blomendahl et al., 2011). Roberts and Schlenker (2013) also argue that the economic development in Asia led to commodity price increases between 2005 to 2008. Serra et al. (2011) and Roberts and Schlenker (2013) find that high oil prices, restrictions on ethanol imports and government policies such as subsidies, tax credits, and the ban of methyl tertiary-butyl ether (MTBE) have spurred ethanol production in the United States. A reduction in ethanol demand would (all else equal) reduce commodity prices. Farmers would see a decrease in their net income and consumers could benefit from lower food prices. If corn prices decline, meat and dairy product prices would follow because corn is an important input in livestock and meat production.

The important changes in U.S. corn demand also affect commodity trade patterns (Elobeid and Tokgoz, 2008; Keeney and Hertel, 2009). U.S. corn exports decline from an average of 54.1 to 45.7 million metric tons over the periods 2003-2006 and 2007-2010, respectively, which represents a decline by $15.5 \%$ (USDA, 2020a). The increase in production has also allowed the U.S. to become a net exporter of ethanol in 2010. Between 2015 and 2018, ethanol exports increased by $125.1 \%$ and peaked in 2018. Elobeid and Tokgoz (2008) present an early assessment of removing trade barriers that were imposed by the U.S. to protect its ethanol industry. A removal of U.S. trade barriers would have decreased the U.S. ethanol price by 13.6\%. Beckman (2015) highlights the increased importance of energy policies to sustain production and consumption of ethanol post2011 slow-down in growth. The author argues that an increase in Brazilian ethanol use in the future reduces the competition between U.S. and Brazilian ethanol in world markets. In our case, the decrease of domestic U.S. ethanol demand can lead to more ethanol available in world markets and thus, increased competition for other biofuel exporting countries and lower world prices.

From an environmental perspective, the global land-use allocation changes resulting from higher commodity prices have triggered significant research efforts especially as it related to carbon emissions (Searchinger et al., 2008; Fabiosa et al., 2010; Hertel et al., 2010; Dumortier et al., 2011; Carriquiry et al., 2019). Without a 20\% life cycle GHG reduction over the 2005 gasoline baseline, corn ethanol would not qualify as a renewable fuel (Lewandrowski et al., 2020). Biofuel feedstock production displaces land away from feed and food production because crops are 
competing for a relatively fixed amount of land (Fabiosa et al., 2010). Thus, the increase in corn demand not only increases the price of corn but also the price of other commodities competing for land. Given the global nature of agricultural markets, these price effects do not remain local but are transferred to the rest of the world leading to global land-use changes based on U.S. policy. Higher commodity prices encourage farmers to increase production through either extensification (i.e., bringing more land into production) or intensification (e.g., increasing fertilizer application and/or using better quality seeds). Extensification leads to the expansion of agricultural land into native grassland and forests, which in turn releases soil and biomass carbon. Searchinger et al. (2008) demonstrated that the carbon emissions from expansion of cropland into native vegetation can potentially increase greenhouse gas (GHG) emissions associated with ethanol significantly. Subsequent research highlights the importance of assumptions regarding agricultural markets in general and crop yield response to higher commodity prices in particular to calculate GHG emissions from ethanol (Hertel et al., 2010; Dumortier et al., 2011; Carriquiry et al., 2019). Incorporating the carbon effects into the life-cycle analysis of biofuels can reduce their environmental benefits although there is a wide range of emission estimates (Carriquiry et al., 2019). Given the interest in land-use change by policy makers, researchers, and stakeholders paired with the actual land use change from higher ethanol production, our study sheds light on the post-peak effects on land and carbon emissions.

The stock of flex-fuel vehicles is projected to increase by $0.48 \%$ annually until 2050 . Thus, ethanol use in flex-fuel vehicles will not compensate for the decrease in ethanol-blended gasoline use (Panel (b), Figure 1). Furthermore, the demand for E85 is highly dependent on the price differential between gasoline (and E10) and E85 (Westbrook et al., 2014; Pouliot and Babcock, 2017). Pouliot and Babcock (2017) find that the demand for E85 increases significantly if there is a $20 \%$ savings on a cost-per-mile basis relative to E10. According to Westbrook et al. (2014), biofuel consumption will not meet the RFS mandate unless the price differential is substantial (feedstock prices below $\$ 100$ per dry ton and oil prices above $\$ 215$ per barrel). We show in this paper that even a higher market penetration of $10 \%$ above the baseline for newly sold light duty vehicles, i.e., cars and trucks, will not significantly increase the demand for ethanol in the short- to medium-run.

\subsection{Ethanol in the European Union}

In 2016, fuel ethanol and biodiesel consumption in the EU was 5.23 and 14.44 billion liters, respectively (USDA, 2018). This represents $9.6 \%$ and $182.7 \%$ of U.S. levels for ethanol and biodiesel, respectively. In December 2018, a revised renewable energy directive was enacted, which set the blending limit for conventional biofuels to 7\% (EU, 2018). The term "conventional" refers to biofuels produced from food and feed crops, which reflects an attempt to address indirect land-use change explicitly (EU, 2018). The blending limit of $7 \%$ represents a significant increase from the current $4.1 \%$ limit.

The EU Commission's report titled "EU Reference Scenario 2016 - Energy, Transport and GHG Emissions Trends to 2050" (European Commission, 2016) serves as the basis for our analysis with regard to fuel efficiency in the EU. The report indicates a decrease of $15.8 \%$ between 2015 and 2050 in energy demand for private cars and motorcycles. In the EU, the energy demand for 
private cars and motor cycles - which represents $70 \%$ of energy use road sector - is projected to decline by $18.5 \%$ over the period $2015-2050 .^{2}$ This is also consistent with projections from the International Energy Agencies, which expects EU biofuels to level off in 2030 (IEA, 2018).

The revised renewable energy directive from the EU sets a binding target of renewable energy in the transport sector of at least $14 \%$ by 2030 and biofuels will play an important role in achieving this target (EU, 2018). Additionally, the EU has set a 2021 target to reduce $\mathrm{CO}_{2}$ emissions from light-vehicles to $95 \mathrm{~g} \mathrm{CO}_{2} \mathrm{~km}^{-1}$ (EU, 2019). Hu and Chen (2016) find that the 2021 target cannot be achieved merely through improvements in fuel efficiency but in combination with downsizing of vehicle size and engine power. These changes in vehicle attributes would have further implications on ethanol use in the EU.

\subsection{Ethanol in Brazil}

Sugarcane ethanol production in Brazil increased from 10.6 to 28.5 billion liters between 2000 and 2015. Vehicle sales data for Brazil from the 2015 Brazilian Automotive Industry Yearbook (Panel (d), Figure 1) show the introduction of flex-fuel vehicles in 2003. With the continued increase in flex-fuel vehicles sales, Brazil has seen a rapid growth in hydrous (E100) ethanol consumption. The country has implemented the RenovaBio policy that sets GHG emission targets and, through financial support to the sector, could incentivize the doubling of Brazilian ethanol production by 2030 (IEA, 2018; Grassi and Pereira, 2019). Schmitt et al. (2011) analyze the implementation of policies promoting vehicle energy efficiency as well as biofuel use on sugarcane area planted and GHG emissions in Brazil. They find that energy efficiency programs and biofuel policies can help reduce GHG emissions. Moncada et al. (2018) determine that a combined policy of a gasoline tax hike and tax-free hydrous ethanol could lead to $100 \%$ increase in ethanol production by 2030. Given the evolution of the fuel economy in the U.S., this could be considered a possible policy for the U.S. in order to maintain ethanol production in the long-run. In 2016, the Brazilian Ministry of Mines and Energy published projections of the future Brazilian Energy Demand (Panel (c), Figure 1) that suggest a continuous increase in ethanol consumption in Brazil. Thus, while we decrease the ethanol consumption in the EU and the U.S, we do not modify the Brazilian ethanol consumption in the scenario. ${ }^{3}$

\section{Modelling Approach}

Given increases in crop yield and a decrease in the expected quantity of feedstock demanded for ethanol, we expect to see a fall in corn prices and a contraction of crop areas as farmers experience a decline in returns to agricultural crop production. Lower domestic prices would create incentives for foreign users to demand U.S. corn. This in turn limits the magnitude of the excess supply generated by a reduction in domestic demand and the size of the price decline. Therefore, analyzing

\footnotetext{
${ }^{2}$ A non-disclosure agreement with the European Commission (Directorate General Mobility and Transport) prevents us from reporting detailed estimations on gasoline and bio-gasoline demand projections.

${ }^{3}$ However, Brazilian ethanol consumption increases by $3.6 \%$ in response to global ethanol price changes in the scenario.
} 
the issue of declining ethanol consumption in isolation from the rest of the world, that is, in the absence of trade, would overestimate the consequences for U.S. agriculture. Because global agricultural markets are integrated, it is important to look at the issue of biofuel demand with a global agricultural outlook model such as the CARD Model used in this analysis. The decrease in gasoline and biofuel consumption modeled in our analysis is driven by the increase in fuel efficiency and current policies (and their sunset date). This is true for all countries modeled. In the absence of any major policy changes, fuel efficiency increases drive the decrease in fuel consumption.

\subsection{Overview of Agricultural Outlook Models}

There are multiple agricultural outlook models besides the CARD Model: (1) Modular Applied GeNeral Equilibrium Tool (MAGNET, formerly LEITAP) of the Agricultural Economics Research Institute (Wageningen University), (2) International Model for Policy Analysis of Agricultural Commodities and Trade (IMPACT) of the International Food Policy Research Institute (IFPRI), (3) AGLINK-COSIMO of the OECD, (4) Global Trade Analysis Project (GTAP) and (5) the Global Biosphere Management Model (GLOBIOM).

A review of the aforementioned models reveals that none of them model the transportation sector explicitly, i.e, as a function of vehicle stock and transportation policies. The MAGNET (formerly LEITAP) - which is at its core a GTAP Model - takes biofuels as given and "only the imposition of a target share is modelled."4 The IMPACT Model separates biofuel demand into an endogenous and exogenous component. It quantifies exogenous biofuel "through exogenous growth rates, which represent government mandates to encourage the production of biofuels" (IFPRI, 2015). OECD's AGLINK-COSIMO Model also divides biofuel demand into an exogenous and endogenous component. The "exogenous one is dependent on mandates and biofuel use" and the "endogenous part is a function of lagged production, the relation between output prices and feedstock costs and a trend component." (OECD, 2015). The standard GTAP model is non-dynamic and compares two states for policy analysis. The model is a very complete general equilibrium model but does not explicitly model the fuel economy and a changing vehicle stock. The documentation for GLOBIOM (https://ec . europa.eu/clima/sites/clima/ files/strategies/analysis/models/docs/globiom_en.pdf) reveals that the model is not "covering the energy sector and is therefore dependent on external projection of bioenergy demand."

The approach to analyze the effects of policy or changes in the economic environment is similar across all of the models. The models (including the CARD Model) generate a baseline with status quo assumptions about policy, technology, and the economic environment. Changes to those parameters are implemented depending on the issue of interest and a scenario is simulated with the new parameters. In our case, this change is a reduction in ethanol consumption in the U.S. and the EU. The baseline is then compared to the scenario and the resulting effects in terms of commodity prices, land-use change, and trade can be attributed to the change in parameters.

\footnotetext{
${ }^{4}$ wWW . magnet-model .org/modules. aspx
} 


\subsection{CARD Model}

As indicated previously, the objective of this paper is to quantify the effects of decreasing ethanol demand on land-use, trade, prices, and GHG emissions in the United States and globally. This requires the use of a global agricultural outlook model, which incorporates production, demand, and trade relationships, and a GHG model to calculate GHG emissions. We use the well-established CARD Model that includes macroeconomic parameters such as oil prices and economic variables (e.g., Gross Domestic Product, exchange rates) as well as government policies (e.g., taxes, subsidies, and tariffs). The CARD Model has been used extensively in the past to evaluate and inform policy and regulatory issues (Searchinger et al., 2008; Elobeid and Tokgoz, 2008; Dumortier et al., 2011, 2012; Elobeid et al., 2012, 2013; Carriquiry et al., 2019).

The CARD Model is a multi-market, partial-equilibrium, and non-spatial econometric model. The model covers all major temperate crops, sugar, biofuels, dairy, and livestock and meat products for major producing and consuming countries. For our analysis, we only analyze the effects that occur in the long-run because the consequences of a reduction in gasoline and ethanol consumption occur over multiple decades and are beyond the time frame of the model. Thus, in the scenario, we impose a path of ethanol reduction, which results in the desired outcome in the last year of the projection. The goal of our paper is to provide a quantitative analysis about the effects of a reduction in ethanol consumption and not to make forecasts until the year 2050, which is the end year of the EIA (2018) and European Commission (2016) projections.

The CARD Model is the interaction of multiple modules modeling specific commodities: grains (e.g., barley, corn, sorghum, wheat), oilseeds (e.g., rapeseed, soybeans), sugar, livestock, and dairy. The various modules interact to determine production, consumption, prices, and trade. The livestock and dairy modules determine demand for beef, chicken, pork as well as milk, butter, and cheese. The livestock model differentiates between stock and flow variables. Herd size is a stock variable based on the decisions of the farmers to modify flow variables such as slaughter or increasing/reducing the breeding herd. These decisions also influence the feed demand, which is used in the grains and oilseed modules. In the grain, oilseed, and sugar modules, the production is determined by the relative profitability between competing crops, which ultimately determines the area planted. The consumption of grains, oilseeds, and sugar is divided into feed and/or non-feed uses (e.g., food, biofuels). For the commodities and countries covered in the CARD Model, agricultural and trade policies are exogenously given. Examples of such policies are import and export taxes, tariffs, quotas, subsidies, price floor, and price ceilings.

The model specifies behavioral equations for production (area harvested and yield for crops), use, stocks, and trade between countries/regions. For each commodity, a number of countries and regional aggregates are included to provide worldwide coverage. In general, for each commodity sector, the economic relationship that quantity supplied equals quantity demanded is achieved through a market-clearing price for the commodity. In many countries, domestic prices are modeled as a function of the world price using a price transmission equation, which includes exchange rates and relevant trade policies. Since econometric models for each sector can be linked, changes in one commodity sector will impact the other sectors. The data sources of the CARD Model are from U.S. Department of Agriculture (USDA), ${ }^{5}$ the United Nations Food and Agriculture Organi-

\footnotetext{
${ }^{5}$ USDA sources used in the CARD Model are the Production, Supply, and Distribution (PS\&D)
} 
zation (FAO), and the International Monetary Fund (IMF).

\subsection{GHG Model}

The GHG Model captures soil and biomass carbon pool changes and emissions from land-use change and is an addition to the CARD Model. It has previously been used to evaluate emissions from biofuel policy (Carriquiry et al., 2019), a tax on U.S. beef production (Dumortier et al., 2012), and biochar application on U.S. cropland (Dumortier et al., 2020). The GHG model covers all crop and livestock categories of the CARD Model and uses Tier 1 default values developed by the Intergovernmental Panel on Climate Change (IPCC) (IPCC, 2006). The land-use component calculates net carbon (C) pool changes and associated $\mathrm{CO}_{2}$ emissions from land moving between forest, grassland/pasture, cropland, and barren/sparsely vegetated land. Since the CARD Model and the GHG Model are global in scale, they can capture any spill-over/leakage effects from one country's policy to other countries.

The model includes global Geographic Information System (GIS) data about global land cover, crop type area, livestock activity, and biomass/soil carbon characteristics. In particular, the spatial distribution of the various crops covered in the CARD Model is obtained from Monfreda et al. (2008) who provides the information at a resolution of $10 \times 10$ kilometers $(\mathrm{km})$. The global distribution of livestock is obtained from the FAO's Global Livestock Production and Health Atlas (GLiPHA) and the Gridded Livestock of the World (GLW) database. ${ }^{6}$ The combination of livestock distribution, livestock production system, and pasture allows for the calculation of country/region specific stocking rates.

To calculate carbon coefficients, we follow the approach described by Gibbs (2006). In a first step, we merge the Global Land Cover 2000 (GLC2000) database with FAO's Global Ecological Zones (GEZ) data (European Comission, 2020; FAO, 2020). The result is a GIS data set with the spatial distribution of ecosystem complexes. Based on the minimum, mean, and maximum carbon coefficients presented in Olson et al. (1983), we calculate the global distribution of carbon coefficients. Gibbs et al. (2007) have used the data to assess reducing deforestation and degradation in developing countries.

Based on the changes between the baseline and the scenario, we calculate emissions from landuse change at the grid cell level $(10 \times 10 \mathrm{~km})$. We assume proportional use of native vegetation, that is, if a grid cell contains $40 \%$ grassland, $10 \%$ forest, and $50 \%$ cropland, then an increase in cropland by 1 hectare (ha) reduces forests by 0.2 ha and grassland by 0.8 ha.

database available at https://apps.fas.usda.gov/psdonline and the USDA Foreign Agricultural Service Global Agricultural Information Network (GAIN) database https://www.fas.usda.gov/databases/ global-agricultural-information-network-gain.

${ }^{6}$ Information on GliPHA is available at http://www.fao.org/ag/againfo/home/en/news_archive/AGA_ in_action/glipha.html. The GIS data associated with the livestock distribution is available at http: //www . fao . org/livestock-systems/en/. 


\subsection{Scenario}

The basis for our reduction in U.S. gasoline consumption are the projections of the EIA under various macroeconomic and vehicle driving scenarios. As mentioned previously, gasoline consumption will continue to decline in the future due to increasing fuel efficiency (Panel (a), Figure 1) (EIA, 2018). Diesel consumption will increase due to an increasing number of freight trucks and a stagnating fuel economy for heavy trucks. The EIA also projects scenarios under different macroeconomic conditions such as high/low economic growth and a high/low crude oil price. Under a low oil price, gasoline consumption is expected to increase by $11.7 \%$ by 2050 compared to consumption in 2016. Under a high-oil price scenario, gasoline consumption would decrease by $51.0 \%$ (EIA, 2018). In this paper, we incorporate the reduction consistent with the AEO reference case. The AEO reference case scenario assumes that the average fuel efficiency of newly sold light-duty gasoline cars increases from 37 miles per gallon (MPG) to 48 MPG (15.7 to 20.4 kilometers per liter) between 2016 and 2050. Over the same time span, the fuel efficiency of light-duty gasoline trucks increases from 27 MPG to $39 \mathrm{MPG}$ (11.5 to 16.6 kilometers per liter).

We integrate the EIA's transportation sector projections of biofuel demand into the CARD Model. We compare a baseline with a scenario that leads to a reduction in ethanol consumption in the U.S. and the EU. The ethanol consumption levels in the baseline are 71.18 and 14.53 billion liters in the U.S. and the EU, respectively. In the scenario, consumption is reduced by $30 \%$ in the U.S. and $29.9 \%$ in the EU, respectively. Brazilian ethanol consumption increases by $3.6 \%$ in the scenario relative to the baseline due to lower prices in the global ethanol market. Biodiesel in the EU is projected to increase in both the baseline and the scenario. The transportation sector projections by the EIA are based on (1) the National Energy Modeling System (NEMS) for the U.S. Annual Energy Outlook and (2) the Transportation Sector Model of the World Energy Projection System Plus for the International Energy Outlook. The VISION Model by the Argonne National Laboratory calculates the carbon emissions of the U.S. road transportation sector based on the EIA's Annual Energy Outlook. However, these models do not focus on the effects of the agricultural sector.

\section{Results and Discussion}

The presentation of the results, which are expressed as percent deviations from the baseline in the last year of the projection period, will focus on the effects of increasing fuel efficiency on (1) U.S. and global agriculture and (2) GHG emissions from land-use change. U.S. agriculture is the most affected by increasing fuel efficiency given the large share of U.S. corn dedicated to ethanol production (about 38\%). The required 2018 feedstock for bioethanol production in the EU is $3.9 \%$ (USDA, 2018) which implies that the impact of the scenario is small for this regions agricultur. There are important policy implications from changes in fuel efficiency requirements or blending limit expansion to $15 \%$ affecting commodity prices, trade, and greenhouse gas emissions. 


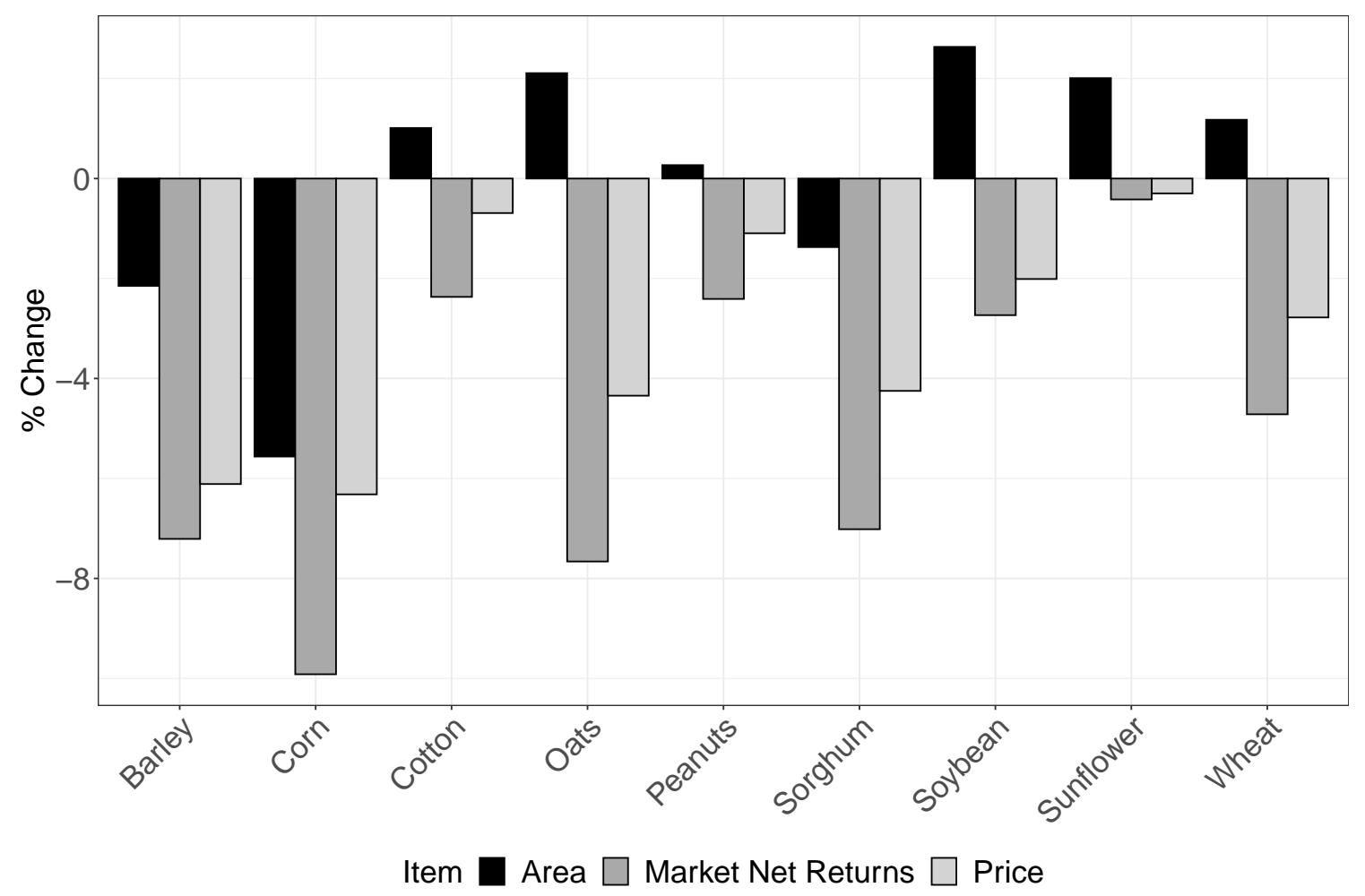

Figure 2. Effects on U.S. agriculture in terms of area harvested, market net returns, and commodity prices. 


\subsection{Effects on U.S. and Global Agriculture}

As expected, the largest farm-gate price response for U.S. commodities is observed for corn with a decrease in price by $6.3 \%$ followed by barley $(-6.1 \%)$, oats $(-4.3 \%)$, and sorghum $(-4.2 \%)$ (Figure 2 ). With the exception of oats, the area harvested for the three other crops also decreases with corn harvested area declining by $5.6 \%$. The prices for wheat and soybeans decrease by less than $3 \%$ as their demand remains relatively strong. The subdued price reduction relative to other crops leads to an increase in area of soybeans and wheat. Feed use for corn increases by $8.2 \%$ in the scenario compared to the baseline, which is due to the reduction in the corn price triggered by the lower ethanol demand. This increase in corn feed use is at the expense of substitute feed ingredients such as wheat and barley for which feed use declines by $12.0 \%$ and 5.9\%, respectively. Except for sorghum, all commodities (i.e., barley, corn, oats, peanuts, soybean oil, sunflower, and wheat) experience increased food use by up to $2 \%$. The decline in market net returns, i.e., the difference between crop revenue and cost, is more pronounced than the price effect alone. The main reason is that a given price reduction results in a larger relative reduction in margins as these are rescaled by costs of production. For corn, the market net returns in the U.S. decrease by $9.9 \%$.

A decline in U.S. commodity prices reduces farm revenue. As indicated in Panel (a) of Figure 1 , a high crude oil price significantly reduces gasoline use while at the same time increasing the operating cost for farmers due to higher prices for energy-intensive inputs. The opposite is true in the case of low oil prices. Although varying oil prices are beyond the scope of our analysis, farmers' welfare can be substantially affected if the reduction in gasoline (and hence ethanol) use is further impacted by the oil price and not only by increased fuel efficiency. If we remain focused on the declining crop prices, livestock producers and ultimately meat consumers will benefit from reduced feed prices. Depending on the magnitude of the decreased ethanol demand on farm income, there are also non- $\mathrm{CO}_{2}$ related environmental consequences. Corn uses high amounts of nitrogen fertilizer, and a reduction in corn price and area reduces runoff. Some farmers may also find it unprofitable to remain in crop production and may retire land into the Conservation Reserve Program (CRP), which has positive consequences such as higher biodiversity and reduced soil erosion. The decline of agricultural area in the U.S. would also have implications on conservation efforts and the CRP. The current U.S. farm bill limits the amount of area in CRP to 24 million acres ( 9.7 million ha) by 2017. A decline in prices due to a decrease in biofuel feedstock demand thus affects land-use and agricultural communities.

Given our scenario of decreased U.S. and EU demand for ethanol, global commodity prices for barley, corn, sorghum, and wheat decrease by $2.5 \%, 6.6 \%, 4.25 \%$, and $2.9 \%$, respectively. The price of soybeans decreases by $1.9 \%$. Because of the reduced demand, the prices for U.S. ethanol and Brazilian anhydrous ethanol decrease by $13.5 \%$ and $10.1 \%$, respectively. Anhydrous ethanol can be blended with gasoline and is exported to the United States (Elobeid and Tokgoz, 2008) and hence, is affected by the reduction in ethanol demand. This highlights fuel efficiency as a supplementary factor influencing commodity prices in addition to oil prices and government policy (Roberts and Schlenker, 2013; Condon et al., 2015).

In response to the decline in corn prices, global corn area decreases by $2.7 \%$, respectively. Except for corn, there is a slight increase in global area for all crops by less than $1 \%$. The total harvested area is reduced in most countries/regions except Argentina, China, and India. The area 


\begin{tabular}{|c|c|c|c|c|c|c|c|c|}
\hline & Barley & Corn & Sorghum & Soybean & SB Meal & SB Oil & Sugar & Wheat \\
\hline \multicolumn{9}{|c|}{ Imports } \\
\hline Brazil & $1.0 \%$ & & & & & & & $0.1 \%$ \\
\hline Canada & & $33.4 \%$ & & & $0.1 \%$ & $26.1 \%$ & $0.3 \%$ & \\
\hline China & $-1.0 \%$ & & & $0.1 \%$ & & $-2.8 \%$ & $-4.7 \%$ & $1.0 \%$ \\
\hline EU & & $14.4 \%$ & & $1.7 \%$ & $-0.2 \%$ & $-3.9 \%$ & $0.1 \%$ & \\
\hline India & & $-131.0 \%$ & $23.6 \%$ & & & $-0.2 \%$ & & $13.3 \%$ \\
\hline Indonesia & & $17.2 \%$ & & & & & $-0.8 \%$ & \\
\hline Japan & $0.1 \%$ & $3.0 \%$ & $1.6 \%$ & $1.5 \%$ & $-0.4 \%$ & $-32.5 \%$ & $-0.1 \%$ & $-0.3 \%$ \\
\hline Malaysia & & $1.6 \%$ & & & & & $0.3 \%$ & \\
\hline Mexico & $3.4 \%$ & $10.1 \%$ & $0.7 \%$ & $0.2 \%$ & $2.6 \%$ & $-2.0 \%$ & & $-0.3 \%$ \\
\hline Russia & & $-75.9 \%$ & & & & & $-3.4 \%$ & \\
\hline Ukraine & & & & & & & $2.8 \%$ & \\
\hline USA & & & & & & & $-0.1 \%$ & \\
\hline Venezuela & & & & & & & $0.0 \%$ & \\
\hline Vietnam & & $11.5 \%$ & & & & & & \\
\hline \multicolumn{9}{|c|}{ Exports } \\
\hline Argentina & $-0.9 \%$ & $-7.3 \%$ & $-1.0 \%$ & $1.5 \%$ & $0.5 \%$ & $0.8 \%$ & $7.0 \%$ & $1.9 \%$ \\
\hline Australia & $0.7 \%$ & $22.5 \%$ & $-2.8 \%$ & & & & $3.3 \%$ & $-0.3 \%$ \\
\hline Brazil & & $-29.8 \%$ & & $-1.9 \%$ & $-2.1 \%$ & $0.5 \%$ & $-2.3 \%$ & \\
\hline Canada & $0.0 \%$ & & & $-1.4 \%$ & & & & $-0.4 \%$ \\
\hline China & & $1.4 \%$ & & & $13.7 \%$ & & & \\
\hline EU & $-2.5 \%$ & & & & & & & $-1.5 \%$ \\
\hline India & & & & $0.0 \%$ & $0.7 \%$ & & $6.3 \%$ & \\
\hline \multicolumn{9}{|l|}{ Indonesia } \\
\hline Malaysia & & & & & & & & \\
\hline Mexico & & & & & & & $-0.4 \%$ & \\
\hline Philippines & & & & & & & $-17.3 \%$ & \\
\hline Russia & $-5.2 \%$ & & & & & & & $-4.1 \%$ \\
\hline Ukraine & $0.1 \%$ & $-5.7 \%$ & & & & & & $1.5 \%$ \\
\hline USA & $-9.5 \%$ & $30.3 \%$ & $4.3 \%$ & $6.3 \%$ & $-1.5 \%$ & $-34.5 \%$ & & $9.0 \%$ \\
\hline
\end{tabular}

Table 1. Changes in imports and exports grains, soybeans including soybean complex with meal (soybean meal) and oil (soybean oil), and sugar. 
of corn in the three countries decreases but is offset by an increase in peanuts and/or rapeseed (only in China and India ) as well as soybeans and wheat (in all three countries). Global and U.S. corn production decreases by $3.6 \%$ and $6.0 \%$, respectively. Due to the reduction in corn price, domestic feed use of U.S. corn increases by $8.2 \%$ at the expense of wheat and soybean meal, which decrease by $9.9 \%$ and $2.5 \%$, respectively, as they become relatively more expensive in feeds.

There are major changes in trade patterns with U.S. corn exports increasing by $30.3 \%$ (Table 1) as a result of lower domestic demand, which creates excess supply and relatively cheaper U.S. corn. This large increase in U.S. corn exports occurs at the expense of other corn-exporting countries such as Argentina, Brazil, and the Ukraine whose corn exports decrease by $7.3 \%, 29.8 \%$, and $5.7 \%$, respectively. Due to the decrease in corn price, all importing countries (with the exception of Russia and India) see an increase in imports. Changes in the trade of barley, sorghum, and wheat are mostly within $\pm 5 \%$.

The total reduction in ethanol consumption in the EU and the U.S. amounts to 6.79 billion gallons ( 25.7 billion liters). Adding the increase of Brazilian ethanol consumption results in a total decrease by 5.75 billion gallons (21.8 billion liters). This corresponds to a decrease of $16.5 \%$ and $30.0 \%$ with and without Brazilian ethanol, respectively.

\subsection{Effects on Greenhouse Gas Emissions}

Global greenhouse gas emissions are reduced due to the overall reduction in cropland. Considering only harvested area for the crops covered in our analysis, the emission reductions range from 188.8 to 468.1 million metric tons of $\mathrm{CO}_{2}$-equivalent $\left(\mathrm{MMT} \mathrm{CO}_{2}\right.$-e) for minimum and maximum emissions coefficients, respectively with a mean of $286.1 \mathrm{MMT} \mathrm{CO}_{2}$-e. The range of value is due to the uncertainty associated with biomass carbon coefficients (Gibbs, 2006; IPCC, 2006). ${ }^{7}$ The global decline in commodity prices leads to an increase in global livestock numbers, which changes the pasture requirements for grazing. Including the increase in global pasture area in the GHG calculations decreases the emission savings from higher fuel efficiency between $5.81 \%$ and $6.71 \%$. Given the reduction in GHG emissions and the decrease in ethanol consumption, the GHG emission savings using the mean carbon coefficients range from 10.5-13.2 $\mathrm{kg}$ of $\mathrm{CO}_{2}$-e per L of ethanol. This is consistent with Carriquiry et al. (2019) who find emissions between 8.3 and $10.2 \mathrm{~kg}$ of $\mathrm{CO}_{2}$-e per L of ethanol. The emission profile by country (Figure 3 ) is a reflection of the land-use changes presented in the previous sections. The reduction in emissions is mostly driven by Brazil, Mexico, and the United States. Cropland reduction in carbon rich areas in Africa are responsible for approximately $40 \%$ in the aggregate category "Other Countries." In a sense increasing the share of global food supplies coming from countries with high yields and relatively low carbon environments such as the U.S. will tend to reduce overall GHG emissions.

\footnotetext{
${ }^{7}$ For details about the minimum, mean, and maximum coefficients, see https://cdiac.ess-dive.lbl.gov/ ftp/ndp017/table.html.
} 


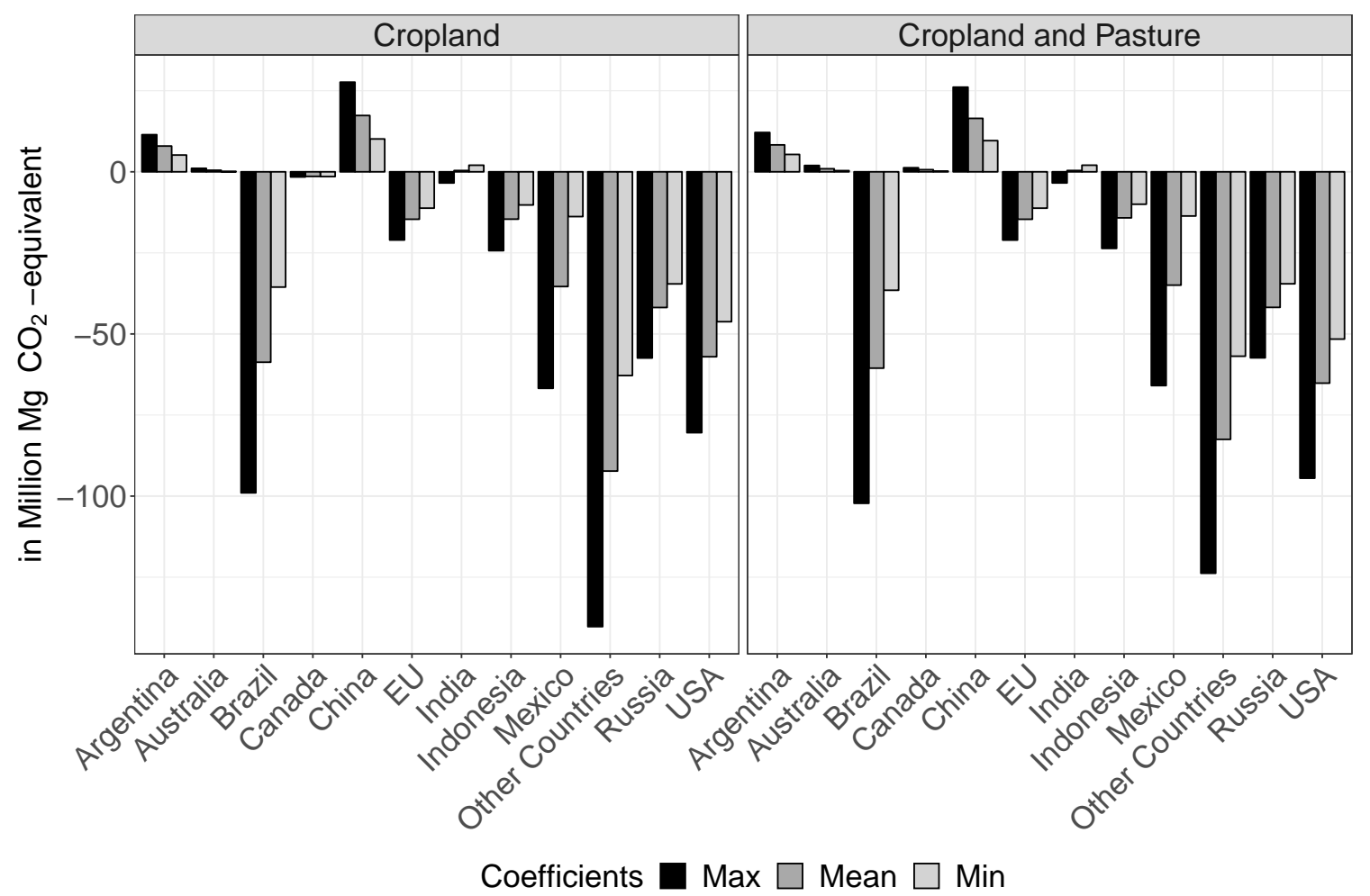

Figure 3. Land-use change emissions in millon metric tons of $\mathrm{CO}_{2}$-equivalent by country. "Cropland" only includes emissions due to a change in harvested area associated with the crops covered in the CARD Model. "Cropland and Pasture" includes changes in pasture area associated with livestock requirements as well. 


\subsection{Sensitivity Analysis}

GHG emissions from land-use change are sensitive to assumptions with regards to commodity yields (Dumortier et al., 2011; Carriquiry et al., 2019). We implement the ethanol reduction in our model over a period of 10 years - which is due to the temporal coverage of the CARD Model - to obtain the commodity price, land-use change, and trade effects. We potentially underestimate the magnitude of the changes because the full reduction in ethanol as modeled in EIA (2018), European Commission (2016), and EPE (2016) would manifest itself over more than 10 years, which would be characterized by higher crop yields due to continued growth. Thus, we conduct a sensitivity analysis by incorporating $10 \%$ higher crop yields in all countries by the end of our projection period for the main biofuel feedstocks (barley, corn, wheat, and sugar). The choice of 10\% was made after reviewing projections for future crop yields Iizumi et al. (2017); FAO (2018). Under the no climate change scenario presented by Iizumi et al. (2017), crop yields for corn increase by a maximum of $6 \%$ over the 20-year period from 2030 to 2050. Over the same time, wheat in the EU is expected to increase by $5 \%$. Those increases are echoed in the business-as-usual scenario of the Food and Agriculture Organization FAO (2018). Over the 20-year period used before, the sugarcane yields in Brazil are projected to increase by $8 \%$. Barley, corn, and wheat in the EU are projected to increase by a maximum of $10 \%$ and corn yields in the U.S. by 6\%. Ray et al. (2013) find higher current annual growth rates of $1.6 \%$ and $0.9 \%$ for corn and wheat, respectively (at the global level) but conclude that overall, crop yields are insufficient to meet food demand by 2050 .

If only cropland is considered, the high increase in yields reduces GHG emissions by 1045.5 and 2261.0 MMT $\mathrm{CO}_{2}$-e for minimum and maximum carbon coefficients, respectively. Using mean carbon coefficients, the decrease amounts to $1430.8 \mathrm{MMT} \mathrm{CO}_{2}$-e. These values represent up to $4.4 \%$ of global GHG emissions (PBL, 2020). If we include pasture into the calculations, the GHG remissions are reduced by 934.5, 1284.3, and 1961.9 $\mathrm{MMT} \mathrm{CO}_{2}$-e for minimum, mean, and maximum carbon coefficients, respectively. The reduction of $1961.9 \mathrm{MMT} \mathrm{CO}_{2}$-e represents $3.8 \%$ of global GHG emissions.

The increase of corn yield in the U.S. and wheat in the EU also has effects on trade patterns. The U.S. corn and wheat exports decrease by $47.5 \%$ and $13.2 \%$ compared to the baseline. U.S. net returns for corn and wheat decrease by $36.4 \%$ and $37.5 \%$ whereas soybean net returns decrease moderately (relative to corn and wheat) by $12.4 \%$. Soybean exports increase by $8.1 \%$. The increase in exports is due to farmers shifting away from corn and into soybean and thus increasing the supply, which results in a lower price. Those large changes are due to combined effect of lower demand for ethanol feedstock and significantly higher grains and sugar yields across the globe.

\subsection{Recent Policy Developments}

On May 31 $1^{\text {st }}$, 2019, the EPA allowed the sale of gasoline blended with $15 \%$ year round. Sale of E15 was previously restricted to the months from June to mid-September because the blend did not meet Reid vapor pressure (RVP) requirements. RVP is a measure of volatility associated with gasoline and other petroleum liquids. Limiting RVP reduces emissions from evaporation (EPA, 2020). While E10 does not meet the RVP requirements, it was granted a waiver by the EPA. Increasing the blending limit to $15 \%$ relaxes the constraints imposed by the $10 \%$ blending limit 


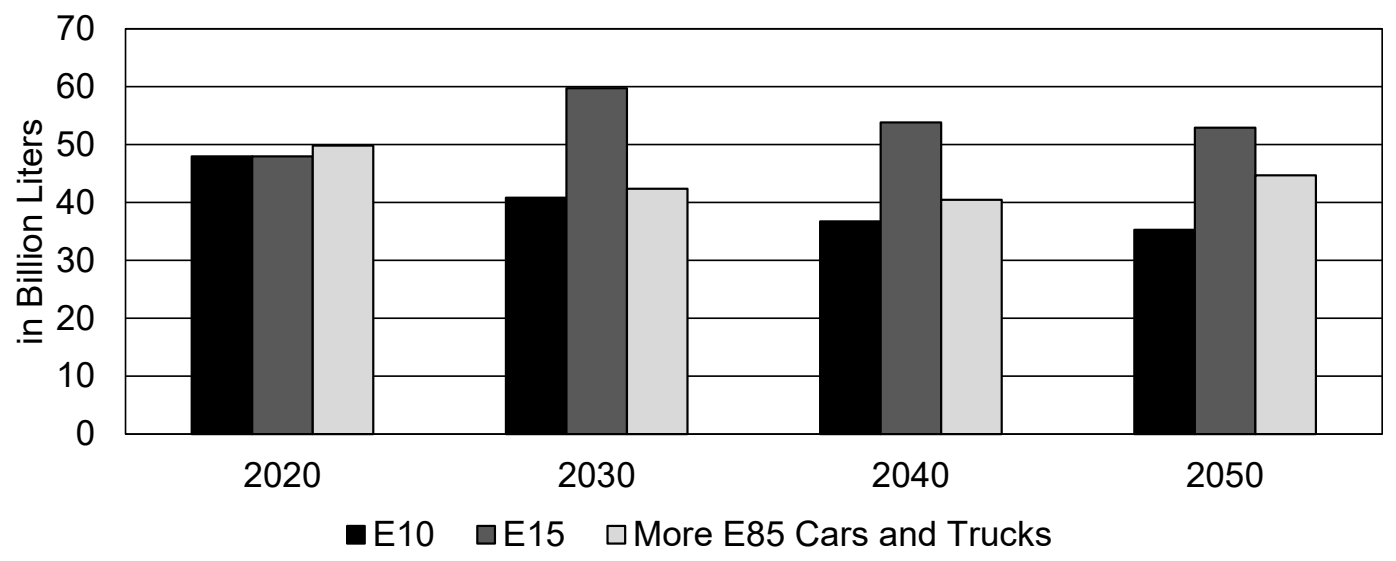

Figure 4. Ethanol consumption based on the VISION Model and the 2018 Annual Energy Outlook under a baseline (E10) and two policy scenarios: (1) Increase to E15 by 2030 and (2) $10 \%$ higher market share of newly sold flex-fuel vehicles between 2020 and 2050.

but does not mean an increase in ethanol domestic consumption by $50 \%$ in the long-run. Once the new blend wall associated with the $15 \%$ is reached, the ethanol consumption will again be tied to gasoline consumption. To illustrate this assertion, we use the 2018 VISION Model by Argonne National Laboratory to conduct an increase of ethanol blending. ${ }^{8}$ In particular, we assume that between 2020 and 2030, the ethanol content of gasoline increases from 10\% to $15 \%$ and remains at $15 \%$ until 2050. Figure 4 shows that the ethanol use in 2050 will be $10.3 \%$ higher than in 2020. Although ethanol consumption will be higher in the short-run from the move to $15 \%$ blending, the higher blend rate suffers from the same issue of declining gasoline consumption in the long-run. The issue raised in this paper is simply deferred into the future but not resolved.

As an alternative policy, we evaluate the increase in market share of newly sold flex-fuel vehicles (i.e., light duty cars and trucks) by 10 percentage points above the current reference case of the 2018 AEO. Figure 4 shows that the effect is not immediate but occurs over time with vehicles trickling into the fleet. This is a policy similar to the approach in Brazil to replace regular gasoline vehicles with flex-fuel vehicles for a growth in ethanol consumption. Note that any policy proposal hinges on the desire to increase ethanol consumption. If the concerns about food prices, land-use change, carbon emissions, or water consumption associated with ethanol production outweigh its benefits then no policy action should be taken.

\section{Conclusions and Policy Implications}

We shed light on the future of biofuel production after a decade of increasing shares of U.S. corn dedicated to ethanol. Projections in the U.S. and the EU suggest that fuel efficiency is increasing

\footnotetext{
${ }^{8}$ https://wWw .anl.gov/es/vision-model
} 
more rapidly than vehicle miles traveled. Because ethanol blending in the U.S. is at the blend wall, domestic ethanol consumption is directly linked to gasoline consumption, which is projected to decline by over $30 \%$ by 2050 . Our results suggest that the future will potentially establish a link between the fuel efficiency of vehicles and commodity prices. Besides increasing fuel efficiency, electric vehicles are slowly increasing their market share in the U.S. and other countries. Both developments result in declining gasoline and biofuel consumption. Our analysis shows that fossil fuel consumption is at a peak in the EU and the U.S. and thus, current domestic markets for ethanol are not sustainable.

The same economic mechanisms that led to commodity price increases and land-use change in the case of biofuel expansion work in the opposite case of biofuel reduction. There are important changes in trade patterns with the U.S. increasing corn exports by over $30.3 \%$ and other cornexporting countries decreasing exports by up to $29.8 \%$ (Brazil). Market returns for U.S. farmers decline by up to $9.9 \%$ for all commodities except canola. This also illustrates the importance of international trade in stabilizing prices. Besides the direct effects of emission reduction from lower gasoline consumption, this paper also highlights the indirect effects in terms of lower GHG emissions from reduced agricultural land-use. We examine the extent to which land-use change can be (if at all) reversed due to increasing fuel efficiency, which affects the use of biofuels. We show that there are significant savings in carbon emissions from avoided land-use change given that, in our projections, less cropland is needed because of reduced ethanol demand, and a higher proportion of crop supplies coming from high-yielding countries. This allows us to examine the environmental impact of policies that affect the transportation sector in the U.S. and elsewhere.

Our model calculates a decrease in the consumption of ethanol but does not take into account the additional increase in commodity yields until 2050 because our model is limited to a 10-year projection period. In the absence of continuing yield increases that are occurring until 2050, we find that effects on commodity prices and land allocation are moderate. Future research needs to cover the entire projection period in both the agricultural outlook model and the road transportation model. We hypothesize that this would exacerbate our results in terms of price, land allocation, and trade. Furthermore, there are complex interactions between vehicle fleet composition, transport policies, agricultural policies and international agricultural markets that need further research. Modeling vehicle stock dynamics based on various policies such as higher fuel efficiency standards or incentives for electric vehicle purchases are necessary to assess the impact of such policies on agricultural markets and the environment. Given the time horizon until 2050, changes in temperature and precipitation triggered by climate change and their effects on commodity yields should be incorporated in future studies. If commodity yields in the U.S. and Europe decline at the same time than a decrease in feedstock demand, the results could potentially offset each other. That is, the decline in feedstock demand is compensated by a decline in crop production potentially stabilizing prices. We leave the test of this hypothesis to future research.

There are major long-term policy implications of our work. Future global biofuel consumption is linked to the evolution of energy use in the road transportation sector. The key aspect is that vehicle composition in a particular country does not change rapidly and - more importantly cannot be changed rapidly by policy. At the center is the linkage between the fuel efficiency of the vehicle stock in a given year and ethanol consumption. The average fuel efficiency of the vehicle 
stock is determined by the vehicle composition (e.g., gasoline versus electric vehicles) and the fuel efficiency of vehicles sold in the previous years. Because the average age of vehicles in the U.S. is over 10 years, an adjustment in average fleet fuel economy does not happen instantaneously but in a multi-year process. Thus, any change in fuel efficiency requirements or policy promoting electric or plug-in hybrid vehicles will have long-term consequences, which affect the fleet average slowly because of the long life-cycle of cars. New cars affected by policy changes will slowly trickle into the market and will initially not have a large effect on energy consumption.

In the U.S. and Brazil, there is currently a strong dependence of agriculture on the future fuel use. Under the status quo, biofuel consumption will decline in the U.S. and the EU that will affect rural welfare. Declining commodity prices will reduce farm income and potentially force farmers to abandon agricultural production. This structural change can increase rural poverty. We also show that from an environmental perspective, the reduction in biofuel use also leads to a reduction in GHG emissions and thus, mitigate climate change. Thus, there is potentially a trade-off between economic support of the agricultural sector and environmental goals such as reduction in GHG emissions and no expansion of cropland into native vegetation. Policy makers interested in continuing biofuel use and income support for farmers have various options. From an environmental perspective, the least desirable option is to relax fuel efficiency standards so as to artificially increase fuel consumption. This is detrimental from an environmental perspective and also does not disconnect biofuels from long-term liquid fossil-fuel based products. Alternatively, the sale of flex-fuel vehicles could be promoted to increase biofuel consumption in the long-run. The increase in flex-fuel vehicles would increase corn ethanol demand in the future but has small immediate impacts. There would also be major implications for global agricultural markets, landuse, and carbon pool changes given the sizeable volume of ethanol demanded in either the U.S. or the EU. Policy makers changing the fuel efficiency requirements for vehicles and interested in the environmental implications in terms of GHG emissions should also take into account the emission consequences due to globally integrated agricultural markets. Lastly, bioenergy can be incorporated in the energy mix for electricity production in the U.S. and elsewhere. Given the electrification of the vehicle stock, agricultural residues and energy crops such as switchgrass and miscanthus can be converted to electricity fueling the road transportation sector. 


\section{References}

ANFAVEA (2015). Brazilian Automotive Industry Yearbook. Technical report, Associação Nacional dos Fabricantes de Veículos Automotores.

Beckman, J. (2015). Biofuel use in international markets: The importance of trade. Economic Information Bulletin 144, USDA Economic Research Service.

Bielen, D. A., Newell, R. G., and A.Pizer, W. (2018). Who did the ethanol tax credit benefit? An event analysis of subsidy incidence. Journal of Public Economics, 161:1-14. DOI: 10.1016/j.jpubeco.2018.03.005.

Blomendahl, B. H., Perrin, R. K., and Johnson, B. B. (2011). The impact of ethanol plants on surrounding farmland values: A case study. Land Economics, 87(2):223-232. DOI: 10.3368/le.87.2.223.

Carriquiry, M., Elobeid, A., Dumortier, J., and Goodrich, R. (2019). Incorporating sub-national Brazilian agricultural production and land-use into U.S. biofuel policy evaluation. Applied Economic Perspectives and Policy. DOI: 10.1093/aepp/ppy033.

Condon, N., Klemick, H., and Wolverton, A. (2015). Impacts of ethanol policy on corn prices: A review and meta-analysis of recent evidence. Food Policy, 51:63-73.

Du, X., Hennessy, D., and Edwards, W. A. (2008). Does a rising biofuels tide raise all boats? a study of cash rent determinants for iowa farmland under hay and pasture. Journal of Agricultural $\mathcal{E}$ Food Industrial Organization, 6(2):1542-0485. DOI: 10.2202/1542-0485.1238.

Dumortier, J., Dokoohaki, H., Elobeid, A., Hayes, D. J., Laird, D., and Miguez, F. E. (2020). Global land-use and carbon emission implications from biochar application to cropland in the United States. Journal of Cleaner Production, 258(120684):1-10. DOI: 10.1016/j.jclepro.2020.120684.

Dumortier, J., Hayes, D. J., Carriquiry, M., Dong, F., Du, X., Elobeid, A., Fabiosa, J. F., Martin, P. A., and Mulik, K. (2012). The effects of potential changes in United States beef production on global grazing systems and greenhouse gas emissions. Environmental Research Letters, 7(2):024023. DOI: 10.1088/1748-9326/7/2/024023.

Dumortier, J., Hayes, D. J., Carriquiry, M., Dong, F., Du, X., Elobeid, A., Fabiosa, J. F., and Tokgoz, S. (2011). Sensitivity of carbon emission estimates from indirect land-use change. Applied Economic Perspectives and Policy, 33(3):428-448. DOI: 10.1093/aepp/ppr015.

EIA (2018). Annual Energy Outlook 2018 with projections to 2050. Technical report, U.S. Energy Information Administration.

EIA (2019). May 2019 monthly energy review. MER DOE/EIA-0035(2019/5), U.S. Energy Information Administration. 
EIA (2020). U.S. product supplied for finished motor gasoline. U.S. Energy Information Administraton database last accessed June $5^{\text {th }}$, 2020. https: //www . eia.gov/dnav/pet/pet_cons_ psup_a_EPMOF_VPP_mbbl_a.htm.

Elobeid, A., Carriquiry, M., Dumortier, J., Rosas, F., Mulik, K., Fabiosa, J. F., Hayes, D. J., and Babcock, B. A. (2013). Biofuel expansion, fertilizer use and GHG emissions: Unintended consequences of mitigation policies. Economics Research International, 708607:1-12. DOI: $10.1155 / 2013 / 708604$.

Elobeid, A., Carriquiry, M., and Fabiosa, J. F. (2012). Socioeconomic and environmental impacts of biofuels: Evidence from developing nations, chapter Implications of global ethanol expansion on Brazilian regional land use, pages 171-190. Cambridge University Press.

Elobeid, A. and Tokgoz, S. (2008). Removing Distortions in the U.S. Ethanol Market: What Does It Imply for the United States and Brazil? American Journal of Agricultural Economics, 90(4):918-932. DOI: 10.1111/j.1467-8276.2008.01158.x.

EPA (2019). Modifications to fuel regulations to provide flexibility for E15; Modifications to RFS RIN market regulations. Federal Register, Vol. 84, No. 111. Docket Number: EPA-HQ-OAR2018-0775.

EPA (2020). Gasoline Standards: Gasoline Reid Vapor Pressure. U.S. Environmental Protection Agency last accessed June 23 ${ }^{\text {th }}$, 2020. https: //www . epa.gov/gasoline-standards/ gasoline-reid-vapor-pressure.

EPE (2016). Plano nacional de energia: Demanda de energia 2050. Estudos da demanda de energia 13/15, Empresa de Pesquisa Energética, Ministério de Minas e Energia.

EU (2018). Directive (eu) 2018/2001 of the european parliament and of the council of 11 december 2018 on the promotion of the use of energy from renewable sources. Official Journal of the European Union last accessed June $5^{\text {th }}, 2020$. https : / / eur-lex . europa . eu/legal-content/ EN/TXT/HTML/?uri=CELEX : 32018L2001\&from=EN.

EU (2019). Regulation (EU) 2019/631 of the European Parliament and of the Council of 17 April 2019 setting $\mathrm{CO}_{2}$ emission performance standards for new passenger cars and for new light commercial vehicles, and repealing Regulations (EC) No 443/2009 and (EU) No 510/2011. Official Journal of the European Union last accessed June $5^{\text {th }}$, 2020. https : //eur-lex . europa . eu/ legal-content/EN/TXT/HTML/?uri=CELEX : 32019R0631\&from=EN.

European Comission (2020). Global Land Cover 2000. Forest Resources and Carbon Emissions (IFORCE) last accessed June $5^{\text {th }}$, 2020. https://forobs.jrc.ec.europa.eu/products/ glc2000/glc2000.php.

European Commission (2016). EU Reference Scenario 2016: Energy, Transport and GHG Emissions Trends to 2050. Technical report, European Commission, Directorate General for Energy, Directorate General for Climate Action, and Directorate General for Mobility and Transport. 
Fabiosa, J. F., Beghin, J. C., Dong, F., Elobeid, A., Tokgoz, S., and Yu, T.-H. (2010). Land allocation effects of the global ethanol surge: Predictions from the international FAPRI model. Land Economics, 86(4):687-706. DOI: 10.3368/le.86.4.687.

FAO (2018). The future of food and agriculture: Alternative pathways to 2050. Report, Food and Agriculture Organization of the United Nations, Rome. Licence: CC BY-NC-SA 3.0 IGO.

FAO (2020). Global ecological zones (gez) mapping. http: //www . fao.org/forest-resources-assessment/remote-sensing/ global-ecological-zones-gez-mapping/en/.

Gibbs, H. K. (2006). Olson's Major World Ecosytem Complexes Ranked by Carbon in Live Vegetation: An Updated Database Using the GLC2000 Land Cover Product. NDP-017b. doi: 10.3334/CDIAC/lue.ndp017.2006.

Gibbs, H. K., Brown, S., Niles, J. O., and Foley, J. A. (2007). Monitoring and estimating tropical forest carbon stocks: making REDD a reality. Environmental Research Letters, 2(4):1-13. DOI: 10.1088/1748-9326/2/4/045023.

Grassi, M. and Pereira, G. (2019). Energy-cane and RenovaBio: Brazilian vectors to boost the development of Biofuels. Industrial Crops and Products, 129:201-205.

Hertel, T. W., Golub, A. A., Jones, A. D., O’Hare, M., Plevin, R. J., and Kammen, D. M. (2010). Effects of US maize ethanol on global land use and greenhouse gas emissions: Estimating market-mediated responses. BioScience, 60(3):223-231. DOI: 10.1525/bio.2010.60.3.8.

Hu, K. and Chen, Y. (2016). Technological growth of fuel efficiency in European automobile market 1975-2015. Energy Policy, 98:142-148.

IEA (2018). World energy outlook 2018. Technical report, International Energy Agency.

IEA Bioenergy (2019). Implementation agendas: 2018-2019 update compare and contrast transport biofuels policies. Technical report, International Energy Agency.

IFPRI (2015). The International Model for Policy Analysis of Agricultural Commodities and Trade (IMPACT): Model Description for Version 3. Discussion Paper 01483, International Food Policy Research Institute.

Iizumi, T., Furuya, J., Shen, Z., Kim, W., Okada, M., Fujimori, S., Hasegawa, T., and Nishimori, M. (2017). Responses of crop yield growth to global temperature and socioeconomic changes. Scientific Reports, 7:7800. DOI: 10.1038/s41598-017-08214-4.

IPCC (2006). 2006 IPCC guidelines for national greenhouse gas inventories. Technical report, Intergovernmental Panel on Climate Change.

Keeney, R. and Hertel, T. W. (2009). The Indirect Land Use Impacts of United States Biofuel Policies: The Importance of Acreage, Yield, and Bilateral Trade Responses. American Journal of Agricultural Economics, 91(4):895-909. 
Lewandrowski, J., Rosenfeld, J., Pape, D., Hendrickson, T., Jaglo, K., and Moffroid, K. (2020). The greenhouse gas benefits of corn ethanol - assessing recent evidence. Biofuels, 11(3):361375. DOI: $10.1080 / 17597269.2018 .1546488$.

Moncada, J. A., Verstegen, J. A., Posada, J. A., Junginger, M., and Weijnen, M. (2018). Exploring policy options to spur the expansion of ethanol production and consumption in Brazil: An agentbased modeling approach. Energy Policy, 123:619-641.

Monfreda, C., Ramankutty, N., and Foley, J. A. (2008). Farming the planet: 2. geographic distribution of crop areas, yields, physiological types, and net primary production in they year 2000 . Global Biogeochemical Cycles, 22:1-19. doi: 10.1029/2007GB002947.

OECD (2015). Aglink-Cosimo Model Documentation: A partial equilibrium model of world agricultural markets. Technical report, OECD.

Olson, J. S., Watts, J. A., and Allison, L. J. (1983). Carbon in live vegetation of major world ecosystems. Environmental Science Division Publication No. 1997 ORNL-5862, Oak Ridge National Laboratory.

PBL (2020). Trends in global $\mathrm{CO}_{2}$ and total greenhouse gas emissions. Report, PBL Netherlands Environmental Assessment Agency.

Pouliot, S. and Babcock, B. A. (2017). Feasibility of meeting increased biofuel mandates with E85. Energy Policy, 101:194-200.

Ray, D. K., Mueller, N. D., West, P. C., and Foley, J. A. (2013). Yield trends are insufficient to double global crop production by 2050. PLOS One, 8(6):1-8. DOI: 10.1371/journal.pone.0066428.

Roberts, M. J. and Schlenker, W. (2013). Identifying supply and demand elasticities of agricultural commodities: Implications for the US ethanol mandate. American Economic Review, 103(6):2265-2295.

Schmitt, W. F., Szklo, A., and Schaeffer, R. (2011). Policies for improving the efficiency of the Brazilian light-duty vehicle fleet and their implications for fuel use, greenhouse gas emissions and land use. Energy Policy, 39:3163-3176.

Searchinger, T., Heimlich, R., Houghton, R. A., Dong, F., Elobeid, A., Fabiosa, J., Tokgoz, S., Hayes, D., and Yu, T.-H. (2008). Use of u.s. croplands for biofuels increases greenhouse gases through emissions from land-use change. Science, 319(5867):1238-1240.

Serra, T., Zilberman, D., Gil, J. M., and Goodwin, B. K. (2011). Nonlinearities in the u.s. cornethanol-oil-gasoline price system. Agricultural Economics, 42(1):35-45.

USDA (2018). Eu biofuels annual 2018. GAIN Report NL8027, U.S. Department of Agriculture Foreign Agricultural Service. 
USDA (2020a). Production, supply \& distribution. U.S. Department of Agriculture Foreign Agricultural Service database last accessed June $5^{\text {th }}$, 2020. https://apps. fas. usda.gov/ psdonline/app/index.html.

USDA (2020b). U.S. Bioenergy Statistics. Corn supply, disappearance and share of total corn used for ethanol database last accessed June $5^{\text {th }}, 2020$. https://www.ers.usda.gov/ data-products/us-bioenergy-statistics/.

Westbrook, J., Barter, G. E., Manley, D. K., and West, T. H. (2014). A parametric analysis of future ethanol use in the light-duty transportation sector: Can the US meet its Renewable Fuel Standard goals without an enforcement mechanism? Energy Policy, 65:419-431.

Zilberman, D., Hochman, G., Rajagopal, D., Sexton, S., and Timilsina, G. (2013). The Impact of Biofuels on Commodity Food Prices: Assessment of Findings. American Journal of Agricultural Economics, 95(2):275-281. 